\title{
André Reboullet, Hugo Vera Meigg. Pedro de Valdivia 641, le collège de l'Alliance Française (1940-1958).
}

LOM Ediciones, Chili, août 2002.

Evelyne Argaud

\section{(2) OpenEdition}

Journals

Édition électronique

URL : https://journals.openedition.org/dhfles/1284

DOI : $10.4000 /$ dhfles. 1284

ISSN : 2221-4038

Éditeur

Société Internationale pour l'Histoire du Français Langue Étrangère ou Seconde

Édition imprimée

Date de publication : 1 juin 2004

Pagination : 186-188

ISSN : $0992-7654$

Référence électronique

Evelyne Argaud, "André Reboullet, Hugo Vera Meigg. Pedro de Valdivia 647, le collège de l'Alliance

Française (1940-1958). », Documents pour l'histoire du français langue étrangère ou seconde [En ligne], 32 I 2004, mis en ligne le 01 janvier 2012, consulté le 27 mai 2021. URL : http://journals.openedition.org/ dhfles/1284; DOI : https://doi.org/10.4000/dhfles.1284

Ce document a été généré automatiquement le 27 mai 2021.

(C) SIHFLES 


\section{André Reboullet, Hugo Vera Meigg. Pedro de Valdivia 641, le collège de l'Alliance Française (1940-1958).}

LOM Ediciones, Chili, août 2002.

\section{Evelyne Argaud}

1 Il n'est pas toujours facile de réaliser un ouvrage qui rende compte d'une aventure dont on a été partie prenante : 20 ans environ de la vie d'un collège de l'Alliance Française au Chili, qui recevait des élèves de 5 ans à 17 ans. Les deux auteurs de l'essai, à mi-chemin entre la monographie et le livre de souvenirs, sont un ancien élève, Hugo Vera Meigg, et un ancien directeur français, André Reboullet, qui fut aussi rédacteur en chef de la revue Le Français dans le Monde de 1961 à 1981. Le projet, dû en partie au hasard, en partie à la volonté initiatrice d'André Reboullet, est né à la suite de retrouvailles entre les deux hommes, après 38 ans de séparation. Le recul du temps et l'émotion ont joué ici un rôle non négligeable.

Modeste dans ses ambitions, puisqu'il s'agissait de faire une simple "plaquette", l'ouvrage compte 181 pages et comporte des textes écrits en espagnol et en français, rédigés par les deux auteurs ou par d'anciens élèves et professeurs. Il s'adresse aux "anciens» (personnel enseignant et administratif, élèves et parents d'élèves) ainsi qu'aux spécialistes de l'enseignement du français au Chili et il se compose de deux grandes parties pour lesquelles les auteurs se sont réparti la tâche. La première, à la charge essentiellement d'André Reboullet, qui a préféré le rôle de l'historien et du pédagogue, est consacrée à l'étude et à l'histoire de l'établissement, depuis sa fondation jusqu'à sa vente, remplacé par un bâtiment neuf, celui de l'actuel lycée Saint-Exupéry de Santiago du Chili. Dans cette première partie, qui débute par un hommage au directeur précédent et à son action, sont expliquées les origines du collège, dont la création a été impulsée par le ministère des Affaires étrangères, désireux de rénover et de reprendre en main un enseignement du français au Chili, tenu alors principalement par des religieux, action qui n'a pas toujours été facile et qui s'est heurtée à des résistances locales. André Reboullet s'intéresse ensuite à la spécificité de ce collège en 
passant en revue ses différents "acteurs " et son environnement, c'est-à-dire ce qui formait l'essentiel de la colonie française à Santiago du Chili : ses institutions, ses associations, ses entreprises et commerces; à cela s'ajoutent des documents qui constituent des sortes d'annexes: listes de professeurs et de promotions d'élèves, complétées pour ces derniers par leurs professions lorsqu'il a été possible de se procurer ces informations. Celles-ci apportent un éclairage intéressant sur les origines de la clientèle du collège et sur ce qu'elle était appelée à devenir socialement et professionnellement.

3 La seconde partie, coordonnée par Hugo Vera Meigg qui s'est réservé «la part du cour », se compose de témoignages d'anciens élèves, écrits le plus souvent en espagnol, faits pour la grande majorité de souvenirs émus, où se perçoivent les marques de la nostalgie et de l'admiration d'un public et d'une époque à l'égard de ce qui venait de la France. Nombreux sont ceux qui évoquent de menues anecdotes de la vie scolaire, des amitiés, des lieux, des visages, des images fugitives, et qui s'accordent à souligner la valeur de l'enseignement reçu à l'Alliance Française, la qualité humaine et pédagogique de son personnel, l'atmosphère conviviale et familiale, l'aspect novateur de ses pratiques éducatives dans un environnement où de telles caractéristiques, d'après certains témoignages, ne semblent pas avoir été fréquentes et où les conditions matérielles n'étaient pas toujours faciles.

4 L'ouvrage donne une bonne image de ce qu'a pu être une de ces Alliances Françaises en Amérique du Sud, avec son journal Chantecler financé par les entreprises françaises locales qui, en retour, bénéficiaient de publicités dans ses pages, avec ses personnages emblématiques, dont l'indispensable homme à tout faire, actif et débrouillard, pour qui l'Alliance a été une promotion sociale, non seulement pour lui-même mais pour de nombreuses personnes de sa famille ou de son village, avec ses fêtes de fin d'année, ses professeurs locaux et détachés, ses élèves français ou nés au Chili de parents français, issus majoritairement de la bourgeoisie aisée et destinés à des professions libérales et intellectuelles. A travers l'examen d'un établissement individuel, il fait renaître une époque, un contexte historique : l'immédiat après-guerre et ses difficultés, une volonté militante, celle de répandre selon les mots de Hugo Vera Meigg "l'excellence de l'esprit et de la culture française ", une volonté éducative liée à la précédente : adopter une attitude expérimentale et s'inspirer des expériences éducatives les plus novatrices (pédagogie Freinet, Montessori). Si l'ouvrage remplit un "devoir de mémoire» selon les mots d'André Reboullet, il porte également les traces de l'émotion qui l'a fait naître et satisfaitle désir de ressusciter un passé, de mesurer l'œuvre accomplie et de rendre hommage aux êtres chers disparus.

\section{AUTEUR}

EVELYNE ARGAUD

INALCO, Paris 